\title{
The First Report of a Patient with Probable Variant Creutzfeldt-Jakob Disease in Turkey
}

\author{
Demet Özbabalık Adapınar ${ }^{\mathrm{a}}$ Suzan Saylısoy ${ }^{\mathrm{b}}$ Çınar Yenilmez ${ }^{\mathrm{c}}$ \\ Hüseyin Asland Bengü Ertan ${ }^{\mathrm{a}}$ Sevilhan Artan ${ }^{d}$ Gülcan Güleç $^{c}$ \\ Çiğdem Susuz ${ }^{a}$ Baki Adapınar ${ }^{b}$
}

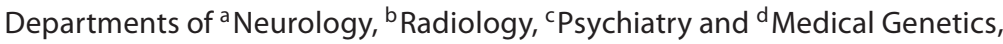
Eskisehir Osmangazi University Medical Faculty, Eskisehir, Turkey

\section{Key Words}

Magnetic resonance imaging $\cdot$ Prion $\cdot$ Variant Creutzfeldt-Jakob disease

\begin{abstract}
Variant Creutzfeldt-Jakob disease (VCJD) was first reported in the UK in 1996. Here, we report the first Turkish case of VCJD. A 47-year-old man, who has never lived outside of Turkey and had had no transfusion, was admitted to the University Hospital with speech disorder, cognitive decline and ataxia following depression, irritability, and personality change. The immunoassay of the 14-3-3 protein in the cerebrospinal fluid was negative. Brain magnetic resonance imaging revealed high-signal lesions involving the bilateral caudate and lentiform nucleus on $\mathrm{T}_{2}$ - and diffusion-weighted imaging. The patient developed akinetic mutism 10 months after disease onset. The clinical presentation and neuroimaging findings were compatible with the vCJD cases reported since 1996 and met the World Health Organization's case definition for probable vCJD.

Copyright $\odot 2011$ S. Karger AG, Basel
\end{abstract}

\section{Introduction}

Creutzfeldt-Jakob disease (CJD), which is characterized by progressive dementia with a fatal and incurable course, is the most common human prion disease. There are 4 types of this disease: the sporadic (85\%), familial (10-15\%), iatrogenic (1\%), and variant types [1]. 
Variant Creutzfeldt-Jakob disease (vCJD) was first reported in 1996 in the United Kingdom and has been causally linked to the consumption of cattle products contaminated with the bovine spongiform encephalopathy (BSE) agent [2]. To date, more than 215 cases of vCJD have been identified worldwide, including in the UK, France, Ireland, Italy, the USA, Canada, Saudi Arabia, Japan, The Netherlands, Portugal, Spain, and Taiwan. In the present paper, we report the clinical and radiological data of the first Turkish case of vCJD.

\section{Case Report}

A 47-year-old man, who was previously healthy and had no history of psychiatric or neurological disorders before the onset of this disease, presented with a 6-month history of progressive behavioral and personality changes, depression, and cognitive decline. His relatives reported that personality changes were his first symptoms. He had been a rigorous, disciplined, and frugal person, who was dependable at work and a valued member of his family; however, he became aggressive, extravagant, foul-mouthed, sexually disinhibited, and angry. His wife reported that the patient would have sudden outbursts of agitation, and 2 months later, these outbursts were followed by paranoid behaviors and possessiveness. Due to the psychiatric nature of his complaints, he was admitted to a psychiatry clinic, where he was diagnosed as having a manic disorder and was given atypical antipsychotic drugs. Three months later, the patient exhibited gait changes, ataxia and dysarthria, severe forgetfulness, difficulties in swallowing and eating, and incontinence. The patient developed involuntary movements in both of his feet, with dystonic aversion-inversion posturing and occasional erratic movements. He became dependent and apathetic and exhibited regressive behaviors. The patient also exhibited visual hallucinations, during which he reported seeing animals. Some of these complaints may have been side effects from his medication and, consequently, several of the patient's medications were stopped or changed.

As a result of the progressive deterioration of the patient's general status, his relatives transferred him to the Psychiatry Department of our University Hospital. After the neurological examination conducted at the Psychiatry Clinic, he was diagnosed as having rapid progressive dementia with early onset and was hospitalized at the Neurology Clinic. As reported in the patient's medical history, he had never been exposed to cadaveric pituitary hormones, had never undergone a neurosurgical procedure, organ or tissue grafts, or a blood transfusion, and had never travelled to the UK or to any country with reported incidences of BSE.

The neurological examination revealed that the patient was disorientated in place and time. In addition, he was mute. Nystagmus and conjugate gaze dysfunction were present, as were cerebellar ataxia, dysmetria, and dysdiadochokinesia. The patient's tone was slightly increased in his lower limbs, and his plantar responses were extensor.

The level of protein in his cerebrospinal fluid was increased, and no 14-3-3 protein was detected. An electroencephalogram showed a generalized slowing of wave, which was more evident in the left hemisphere, but did not have any periodic complexes. He was referred to the Radiology Department for cerebral MRI. On $\mathrm{T}_{2}$-weighted images and fluidattenuated inversion recovery (FLAIR) images, hyperintense signal changes in the bilateral caudate nuclei (white arrows) and the lentiform nucleus (black arrows) were seen. In addition, hyperintensity in the bilateral thalamic region was less prominent than in the previously described areas (fig. 1a-c). Cortical hyperintensity was noted on diffusionweighted imaging.

Genotyping of the prion protein gene (PRNP) identified a P102L mutation and heterozygosity for methionine at codon 129 . 

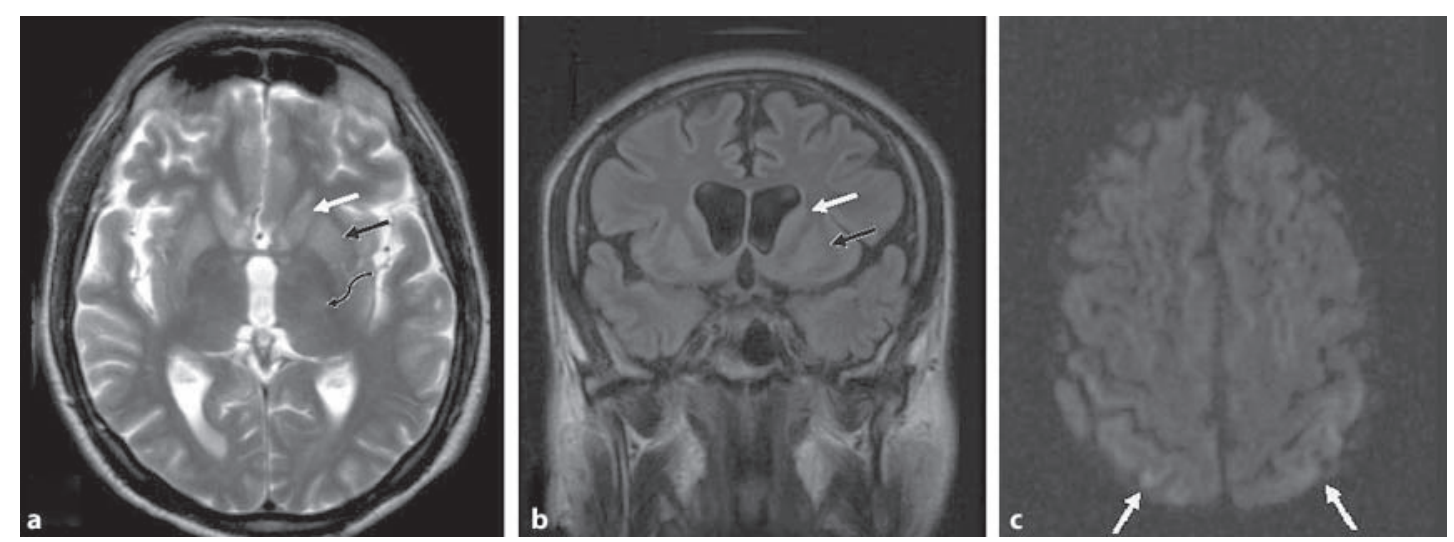

Fig. 1. MRI shows hyperintensity in the bilateral caudate (white arrows) and bilateral lentiform nucleus (black arrows) as well as in the bilateral thalamus (curved arrow) on axial $\mathrm{T}_{2}$-weighted image (a) and coronal FLAIR image (b). Ribbon-shaped hyperintense signals in the right central sulcus and bilateral parietal cortex at the convexity is seen on diffusion-weighted imaging (arrows) $\left(b=1,000 \mathrm{~s} / \mathrm{mm}^{2}\right)(\mathbf{c})$.

The patient did not want to undergo a brain biopsy, and we continued to follow his progress at his home. At the time this report was written, the patient was alive, mute, and on bed rest.

\section{Discussion}

The patient described in the present report was the first probable case of vCJD in Turkey. The clinical features of this patient are consistent with the vCJD cases that have been identified in the UK and France, including psychiatric manifestations at the disease onset, a delayed occurrence of neurological signs, ataxia, and dementia [3]. In addition to the pulvinar sign that was present on the MRI and EEG, the patient fulfilled the WHO case definition for probable $\mathrm{vCJD}$, the specificity of which is $100 \%$ [4]. Of note, a tonsil biopsy is not necessary if the clinical features and the MRI findings are compatible with $\mathrm{vCJD}$, as the pulvinar sign is highly characteristic [5].

Sequencing analysis revealed that the patient had two different nucleotide changes in the coding region of the PRNP gene. The first one is the M129V polymorphism, and our patient was heterozygous for this alteration. Interestingly, all the patients who have undergone genotyping up to now have been homozygous for methionine at codon 129 . This polymorphism is associated with susceptibility to prion diseases [6]. The second one is the P102L mutation, which was first identified in affected members of two unrelated families with Gerstmann-Sträussler disease. P102L is one of the most common PRNP mutations and also related to CJD.

This case highlights the difficulties in achieving an early diagnosis of vCJD. At the initial presentation, a variety of diagnoses were proposed, but $\mathrm{vCJD}$ was not considered in this patient. Instead, he was diagnosed as having an affective disorder at the psychiatry clinic. The delayed neurological signs in this patient pointed to the possibility of progressive dementia, which is not surprising given the frequency of psychiatric features that are observed by primary care physicians. These clinical features are often misleading. Almost half of the cases of VCJD were reviewed by a psychiatrist prior to the patients' neurological referral [7]. A neu- 
rological etiology was usually suspected promptly after the patients developed objective neurological features, which resulted in a neurological referral in all of the cases. The single most important determinant of early diagnosis was the presence of objective neurological features. For this reason, all physicians must be careful when diagnosing rapidly progressing dementia that begins at a young age.

The results presented in this report indicate that patients with vCJD are still seen in the medical community. In the present study, we have reported the first Turkish vCJD case, which appeared 15 years after the first case in the UK.

\section{References}

1 Johnson RT: Prion diseases. Lancet Neurol 2005;4:635-642.

-2 Will RG, Ironside JW, Zeidler M, Cousens SN, Estibeiro K, Alperovitch A, Poser S, Pocchiari M, Hofman A, Smith PG: A new variant of Creutzfeldt-Jakob disease in the UK. Lancet 1996;347:92.

-3 Brandel JP, Heath CA, Head MW, Levavasseur E, Knight R, Laplanche JL, Langeveld JP, Ironside JW, Hauw JJ, Mackenzie J, Alpérovitch A, Will RG, Haïk S: Variant CJD in France and the United Kingdom: evidence for the same agent strain. Ann Neurol 2009;65:233-235.

4 World Health Organization: The revision of the surveillance case definition for variant CreutzfeldtJakob disease (vCJD). WHO/CDS/CSR/EPH/2001.5, 2002. Report of a WHO consultation.

-5 Collie DA, Summers DM, Sellar RJ, Ironside JW, Cooper S, Zeidler M, Knight R, Will RG: Diagnosing variant Creutzfeldt-Jakob disease with the pulvinar sign: MR imaging findings in 86 neuropathologically confirmed cases. Am J Neuroradiol 2003;24:1560-1569.

-6 Lukic A, Beck J, Joiner S, Fearnley J, Sturman S, Brandner S, Wadsworth JD, Collinge J, Mead S: Heterozygosity at polymorphic codon 219 in variant Creutzfeldt-Jakob disease. Arch Neurol 2010;67: 1021-1023.

7 Lépine J, Gastpar M, Mendlwicz J, Tylee A: Depression in the community: the first pan-European study DEPRES (Depression Research in European Society. Int Clin Psychopharmacol 1997;12:19-29. 